\title{
Assessment of 3D Models Used in Contours Studies
}

\author{
F.J. Ayala Alvarez ${ }^{1,2,}$, E.B. Blazquez Parra ${ }^{2}$, F. Montes Tubio ${ }^{3}$ \\ ${ }^{1}$ Department of Building and Civil Engineering, Politécnico Jesús Marín Technical Secondary School, Spain \\ ${ }^{2}$ Department of Graphic Engineering, Design and Projects, University of Malaga, Spain \\ ${ }^{3}$ Department of Graphic Engineering and Geomatics, University of Córdoba, Spain
}

Copyright $@ 2015$ by authors, all rights reserved. Authors agree that this article remains permanently open access under the terms of the Creative Commons Attribution License 4.0 International License

\begin{abstract}
This paper presents an experimental research focusing on the view of first year students. The aim is to check the quality of implementing 3D models integrated in the curriculum. We search to determine students' preference between the various means facilitated in order to understand the given subject. Students have been respondents to prove the hypotheses about the 3D models used in class to explain and do exercises about contours in Topography, and to develop a final course project. A positive attitude of the students towards used 3D models has been observed. Data support our hypotheses.
\end{abstract}

Keywords Augmented Reality, Engineering Drawings, Engineering Students, Modeling, Qualifications, Topography, Virtual Reality, Visualization, Training

\section{Introduction}

In this paper, it is presented how 3D models have been introduced in the teaching-learning process in Vocational education and training (VET), in order to improve students' spatial visualization skills in relation with contours in earthworks in Topography. It is intended to assess the changes made in it. On the other hand, it was aimed to compare several of these means of three-dimensional support, evaluating the preferences of students in the learning process between them. (Augmented reality (AR), using Trimble SkechtUp program (SKP) or an option of pdf file in three dimensions (3D), (PDF3D)). They are shown in Fig. 1, 2 y 3.

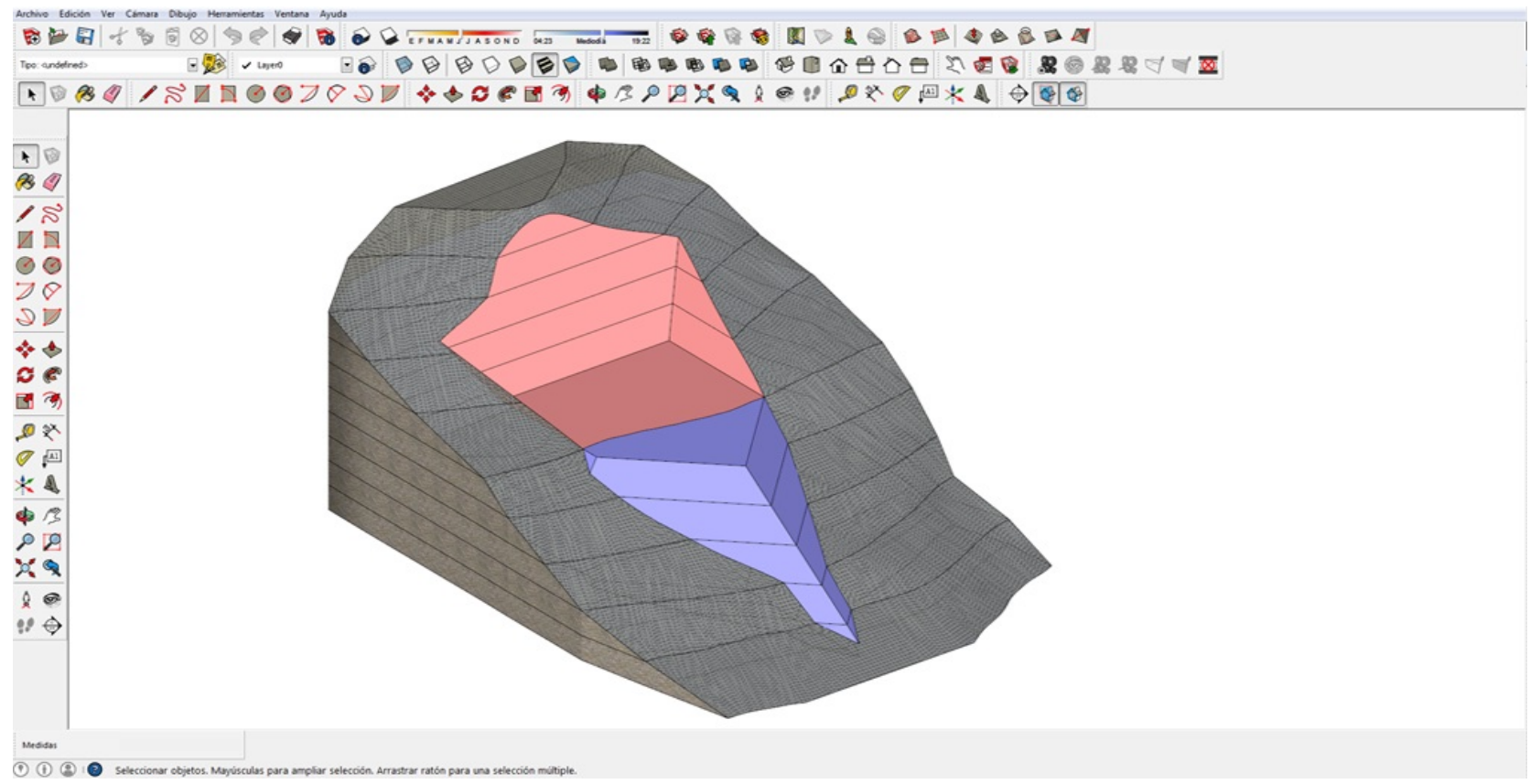

Figure 1. SketchUp display example. 


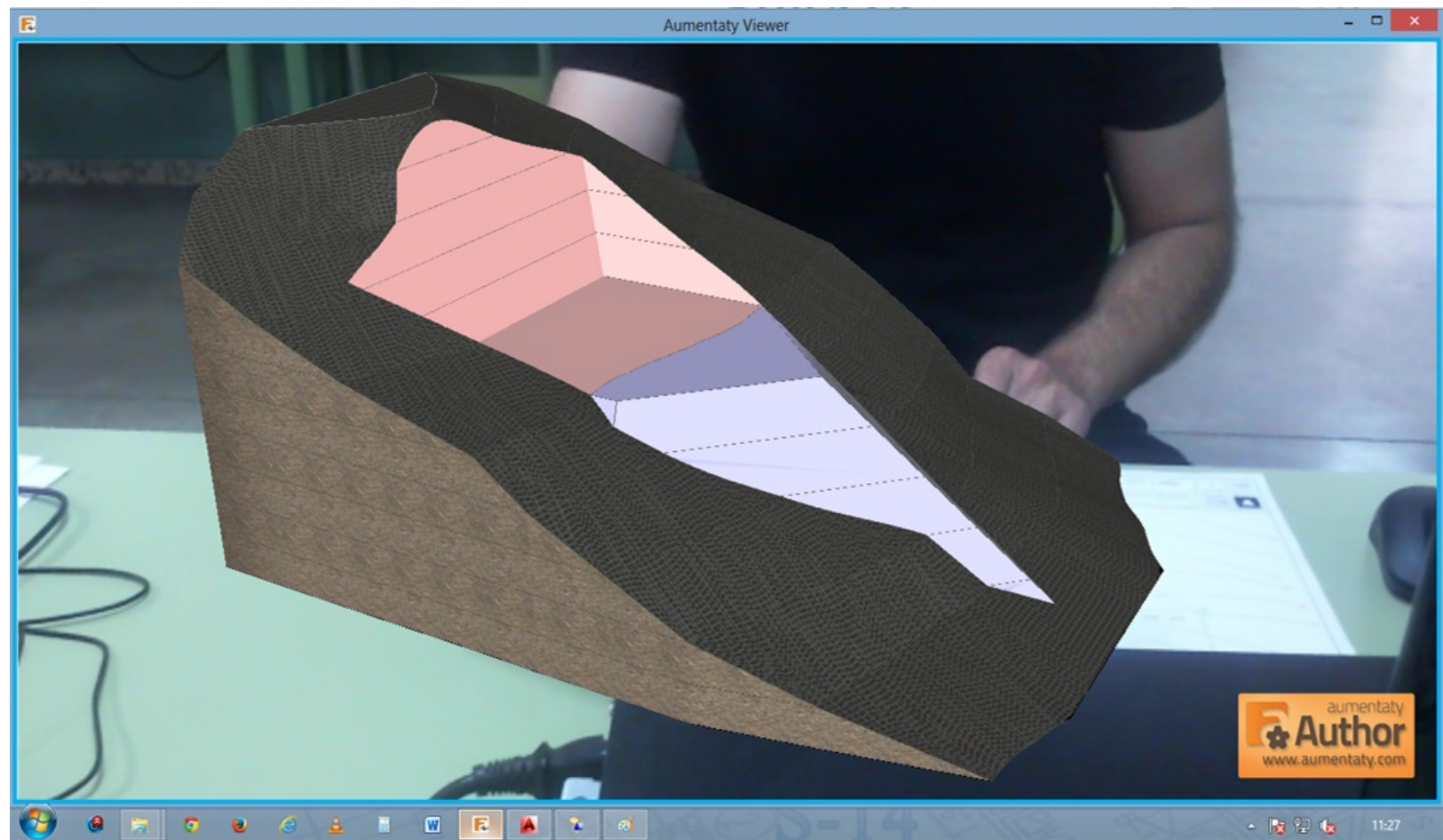

Figure 2. Augmented Reality display example.

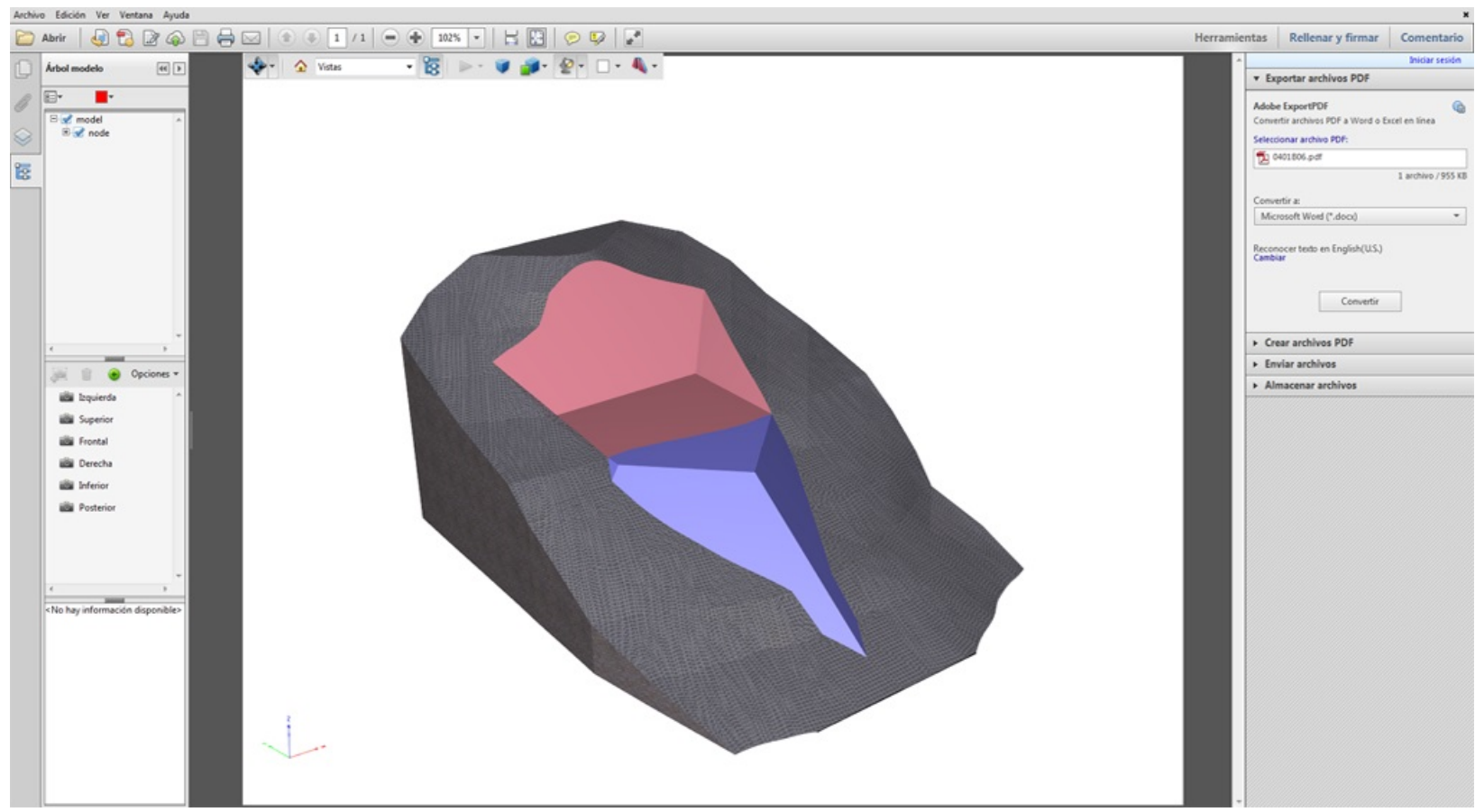

Figure 3. PDF3D display example. 


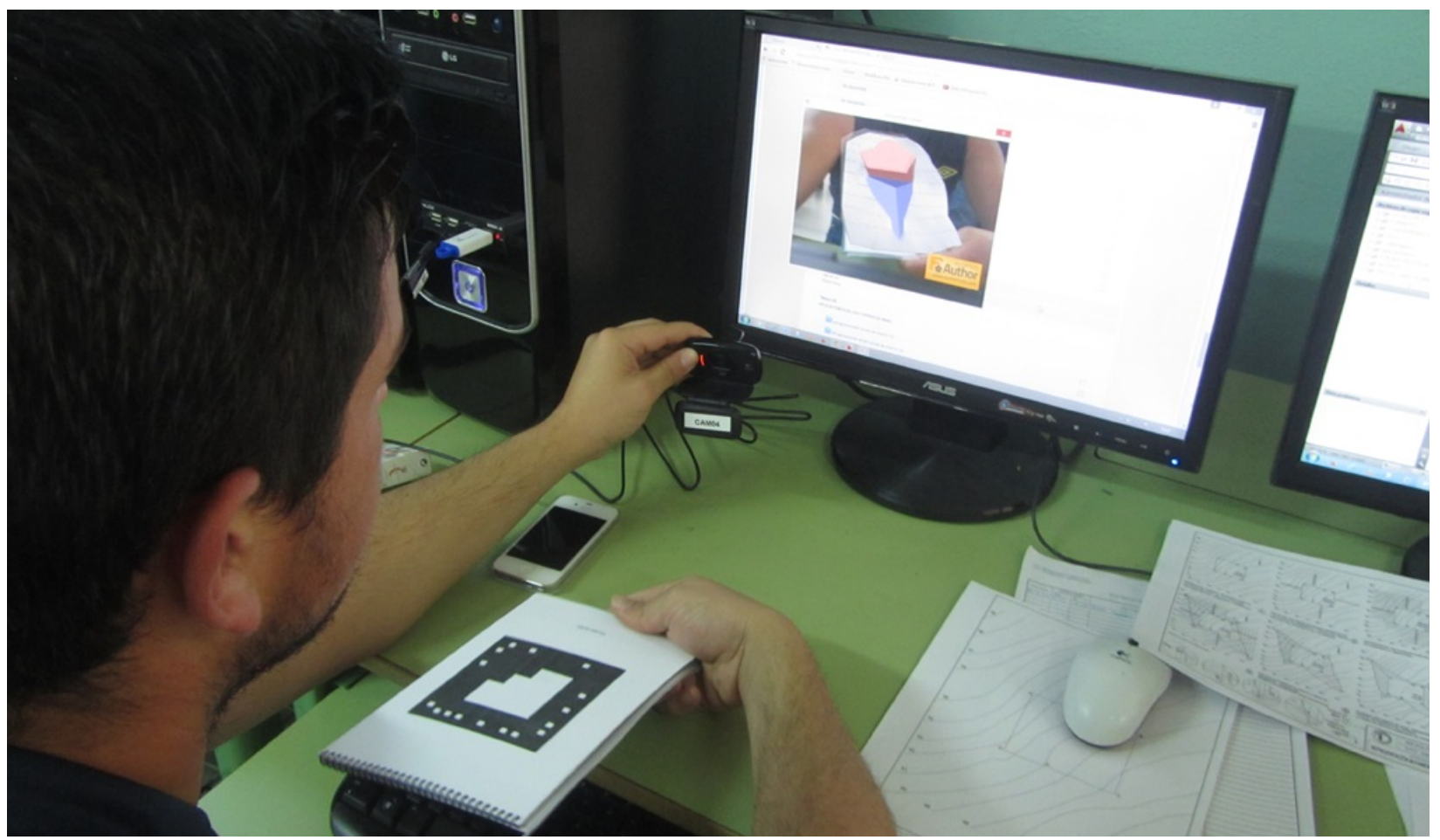

Figure 4. Using 3D model in conducting exercises in class.

Therefore, in course development and in all teaching units relating to the representation of the terrain by contours, series 3D models have been designed in order to accompany explanations by teacher and exercises performed by students during the course, see Fig.4.

Students have answered several batteries of tests for collecting data to determine their technological profile on the use and knowledge of new information and communication technologies, as well as their previous experience and mastery of 3D models and the subject to deal with.

At the end of the experiment there is an evaluation of the system used, the preferences of the students and their level of acquisition of spatial visualization skills referring to contours in the representation of the terrain. Also, a satisfaction survey on the realized course is carried out.

On the other hand, this technology can be used by students to show the result of their final urbanization project, which has developed during the course. Thus, people outside the project, such as the case of any potential purchaser of the product, are able to understand the project when they see it.

\subsection{Background}

Many times students cannot carry out implementation tasks in class because they don't understand what or how to do the exercise. In addition, they need to develop their spatial visualization skills to understand the rest of the relative contents.

Moreover, teachers are not able to supervise the development process as much as they would like to, and students would prefer more support from their teachers in order to solve their doubts.
In this context, a tool has been proposed in several studies: The use of 3D models using different technologies, to assist the teacher in the process of exposing the contents of the didactic unit and help students improve spatial vision problem to better understand the issue.

In Mechanical Engineering, similar studies [1] assert the effectiveness of using models to teach and learn engineering in different subjects: to obtain the third angle orthographic projection model with simple pieces, to show the types of holes, slots, sections and joints and their preparation models in mechanics models and, finally, structural steel construction models.

Others have focused on the application of AR for learning mechanical parts representation [2], standard mechanical elements in studies of Mechanical Engineering [3-5], in electromechanical engineering studies with mechanical parts something more complex [6], to learn sketching, designation and normalization of mechanical elements following ISO standardization international rules [7] and in kinematics [8].

From Fine Arts, the use of a modeling workshop with Trimble SketchUp 3D to develop skills is proposed in a paper [9], showing as a good choice to increase the spatial ability of participants. Other study [10] has compared AR-based design communication with traditional 2D drawings in media presentation.

In the Architecture field, Redondo et al. [11] propose in their study the use of ICT tools and 3D technologies instead of traditional drawing because students get better results on their graphic training, visual education, spatial understanding, academic results and satisfaction. Another paper [12] assert contemporary CAD solutions should be taught from the very beginning of architectural education 
parallel with the classical design methods, because the future belongs to those who will start to use the 3D models as early as possible.

Regarding the AR in the teaching of architecture there are several applications such as VisAr3D [13] o U-AR [14]. The experiments [15] carried out confirmed that AR used, allows improving learning processes and reducing its duration at a very low cost.

The use of AR has been studied in other similar applications [16] and is concluded that it is a technology with great potential for implementation, in heritage as well as in facility maintenance issues and in urban design education [17].

In Building Engineering field, a paper [18] addresses the use of the 3D building models in the computer program SketchUp in activities which allow students to dissect the building structure and develop an understanding how building components interrelate positively. Fonseca et al. [19] propose an AR learning process in the Building Engineering Degree in order to use mobile technologies, AR and digital sketching (DS) in different case studies.

In [20] authors present an AR whose results have illustrated the feasibility in visually imparting basic civil engineering knowledge about construction equipment and 3D simulated construction operations to students with a software termed ARVita [21].

In Earth Sciences and Geology, Rapp et al. [22], assert that when students attempt to comprehend topographic maps, they preferred maps with three-dimensional clues more than maps without them. In addition, we have seen how the sandbox is used to study erosion dynamics of an uplifting landscape [23] and the explanation of sorting out the principles that determine the formation of faults, mountains, rift valleys, and other tectonic features [24] and helps students with the development of their spatial skills [25]. Furthermore, in the same field, the results from the other investigation [26] indicate that it is feasible to use standard smart phones and tablets for geological visualization enhanced with AR fieldVis in educational geological applications.

Other similar studies using virtual models to reach a better understanding of the contours and improve spatial skills applied in orienteering [27] in real and virtual environments.

In topography, also models have been used to convey information in class: sandbox models [28], digital techniques [29] and augmented reality (AR) [30], so that students understand topographic maps and visualizing the $3 \mathrm{D}$ information contained.

In the previous lines, it has been tried to show that in various branches of knowledge in the teaching-learning process, it has been used 3D models (physical, virtual and augmented reality) as tools to improve the spatial ability of students, showing in this paper a comparison of the use of different 3D models (PDF3D, SKP and AR), observing the preferences of students and variation in the spatial ability and in the academic results.

\section{Materials and Methods}

\subsection{Objectives}

This article is pretend to assess the effectiveness of communication using 3D models using different technologies (AR, SKP and PDF3D models), in the teaching-learning process in the management of the contours in Topography, showing the preferences observed by students who have used them against other media, (drawings made manually, charts, teacher explanations, ...), their level of acquisition of spatial skills with contours and their satisfaction.

As specific learning goals we can name:

- Understand and draw different reliefs of land using contours.

- Deduct simple parameters of the drawings made with contours.

- Correctly handle the contours for the representation of earthworks and terrain profiles.

- Calculate the volumes of land involved in a work represented with contours.

\subsection{Academic Context}

The project consists of evaluating the inclusion 3D models in class, gauging the impact of these instruments as a means of transmitting knowledge in VET, more specifically in a Course of Building Projects in a secondary education, (Politécnico Jesús Marín Technical Secondary School in Málaga, Spain).

The experiment is part of the POL+AR Project [31] (Politecnico and Augmented Reality), which belongs to a higher project called Gutenberg3D. POL + AR project intended the implementation and promotion of AR in the process of learning of the graphical representation of elements of engineering and architecture.

It has been applied in a first-year subject called construction stakeout, (7 ECTS credits), yearly compulsory subject in the curriculum, during the 2012-13, 13-14 and 14-15 courses.

\subsection{Working Hypotheses}

In this section, the working hypotheses are presented.

\section{Management of ICT}

The knowledge and level of ICT skills is high. The used medium, (3D digital models), does not limit future learning of contours.

\section{Skill level of associated academic principles}

There is great disparity in relation to the students' control in trigonometry, scales and others basic principles associated. 


\section{Learning through 3D models}

Provided models are suitable for students to improve understanding and management of the contours. It is thought that students will obtain better academic results if they have higher level of spatial visualization skills.

In order to validate most of hypotheses, data obtained from surveys that have been completed by the participants are provided.

\subsection{Methods and Techniques}

3D models have been used as a support in expository class, in development of problems in class and in the development of projects without entailing any change of instructional model.

The Theoretical model of assessment of knowledge acquisition followed in this study has been the one developed by Nunes [32].

\subsection{Instruments}

Considering the data which we needed for the study, the chosen instrument was a questionnaire. A combination of qualitative and quantitative evaluation methods has been used.

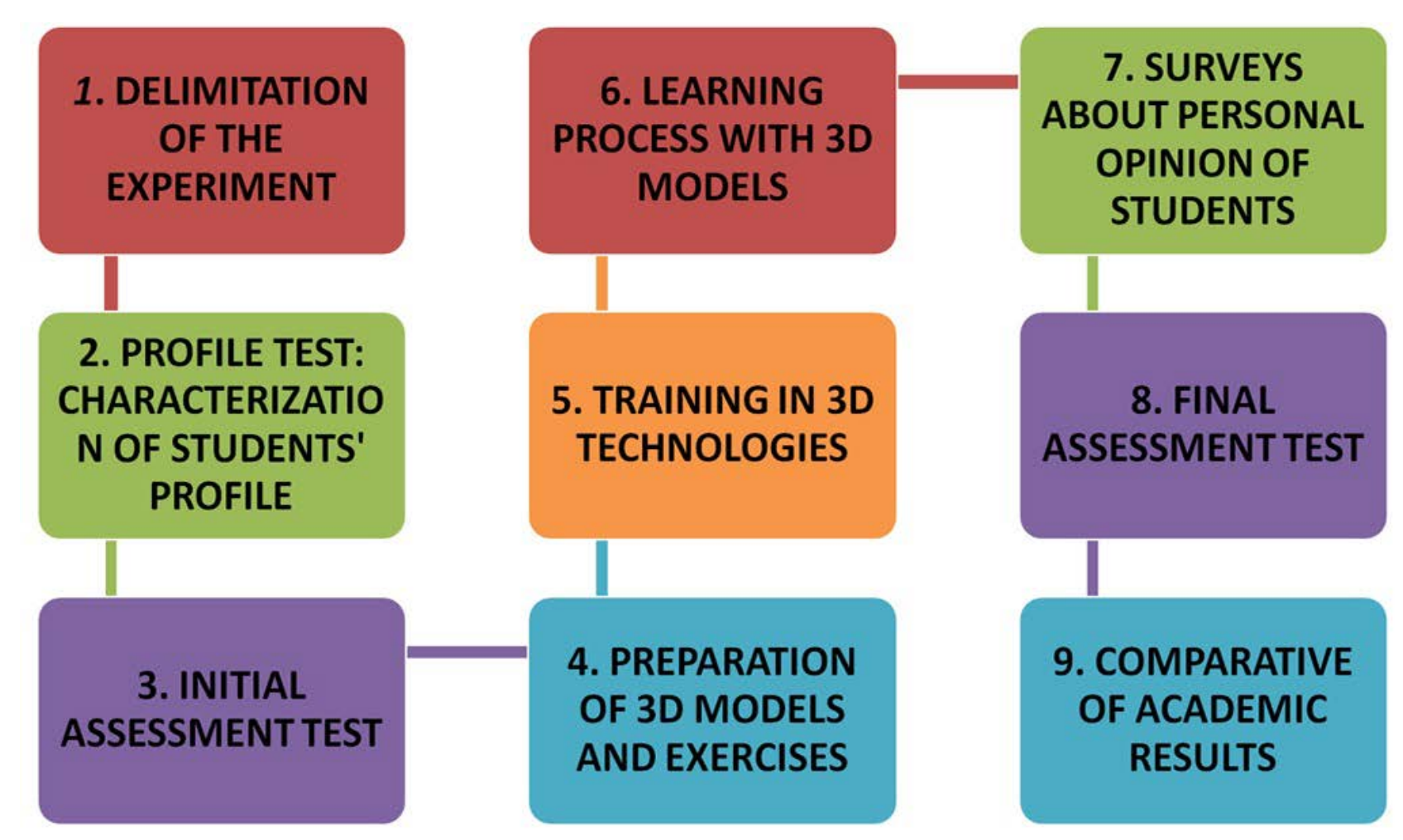

Figure 5. Theoretical Model for Assessment of Knowledge Acquisition.

\subsection{Phases}

Nine phases shape the experimental process, see Fig. 5:

\section{Delimitation of the experiment}

In this stage, it was defined: delimitation of spaces, materials and applications required, subject and the students under study and, on the other hand, the used technologies to create 3D models: (AR, SKP, PDF3D) which complement the explanations given by the teacher using slides, sketches on the blackboard or physical models.

\section{Profile test: Characterization of students' profile}

Several surveys were performed to define demographic data, observe their user profiles in computer, as well as personal appreciations about their knowledge in mathematics, topography and their positioning against new technologies to use.

\section{Initial Assessment Test}

Previous experiences and initial level of knowledge of contours of the students were evaluated. The results obtained in these tests will be compared with those obtained in similar tests, conducted at the end of the process, with equivalent difficulty of teaching to compare the values obtained in both. 


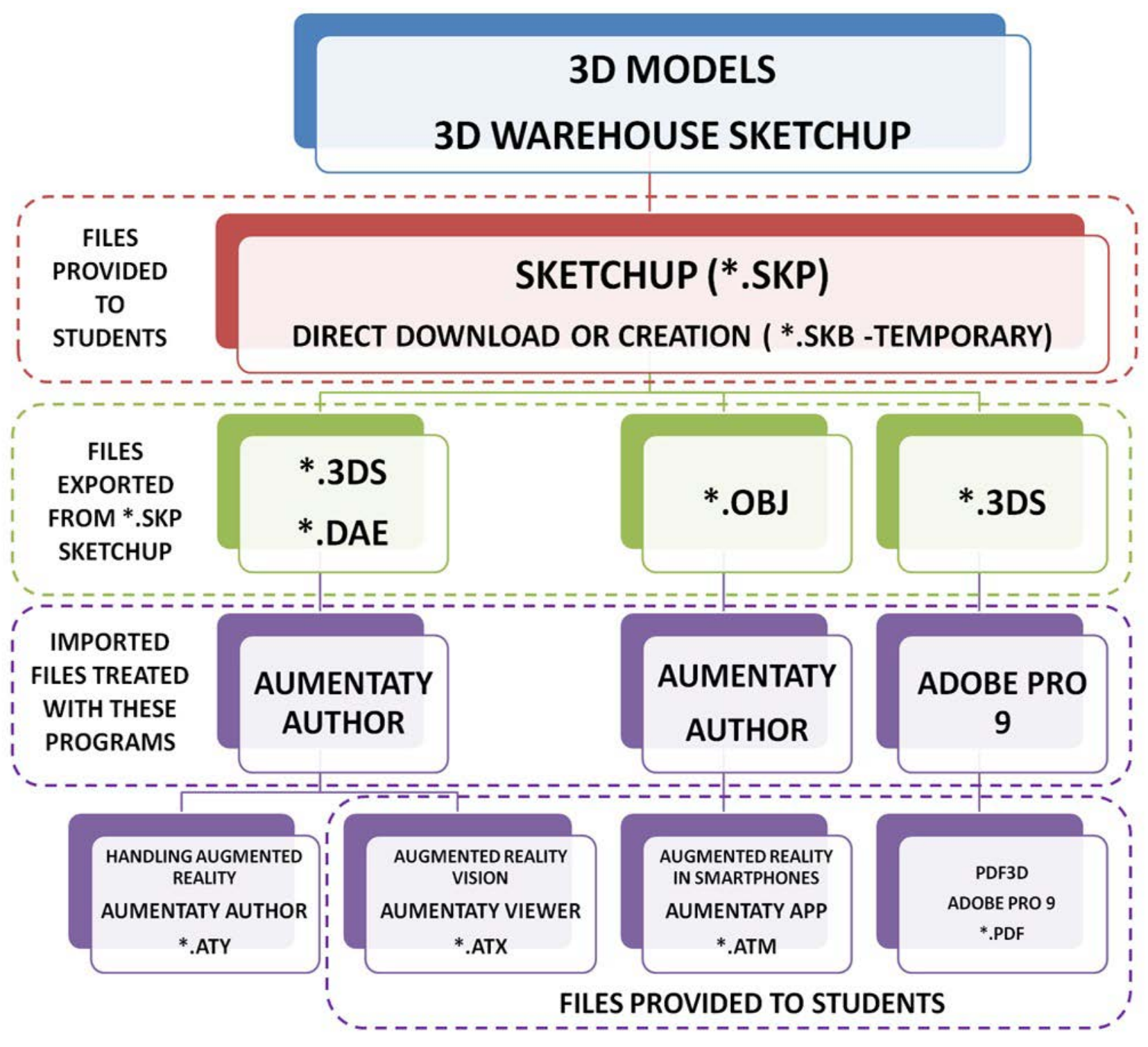

Figure 6. Phases in obtaining digital models.

\section{Preparation of $3 D$ Models and exercises}

In this phase, activities and associated 3D models were created which complemented the topics, activities and exercises that were to be developed in relation to the contours to achieve developing desired competencies. So models have centered on activities in order to improve efficiency in the transmission of knowledge and to encourage active participation, seeking greater participation and autonomy of students. Regarding the preparation of the material, we followed guidelines defined in [33], process detailed in Figure 6.

\section{Training in 3D technologies}

Before the learning process, students received the necessary instructions to handle 3D models without any trouble. To do this days before conducting these exercises, the student could get through Moodle, pen drive devices or Google Drive, in the appropriate format, 3D models and a guide in which the exercises are given to do and theoretical and procedural aspects of the exercises and the fiducial markers.

\section{Learning process with $3 D$ models.}

3D models have been used in several ways: in the exhibition class, Fig. 7, with short exercises or the execution of a project over a long period of time. In all cases the students could manipulate the information on their computer or mobile device simultaneously as needed. Everything could be accompanied with support on the board and / or using PowerPoint slides. The learning process was developed with different types of 3D models. Sometimes students only use $2 \mathrm{D}$ representation to do exercises in order to compare the difference of the experiences.

\section{Surveys about personal opinion of students}

In this final phase, a range of feedback questionnaires were applied in order to collect the students' satisfaction, preferences and the quality of the 3D models. 


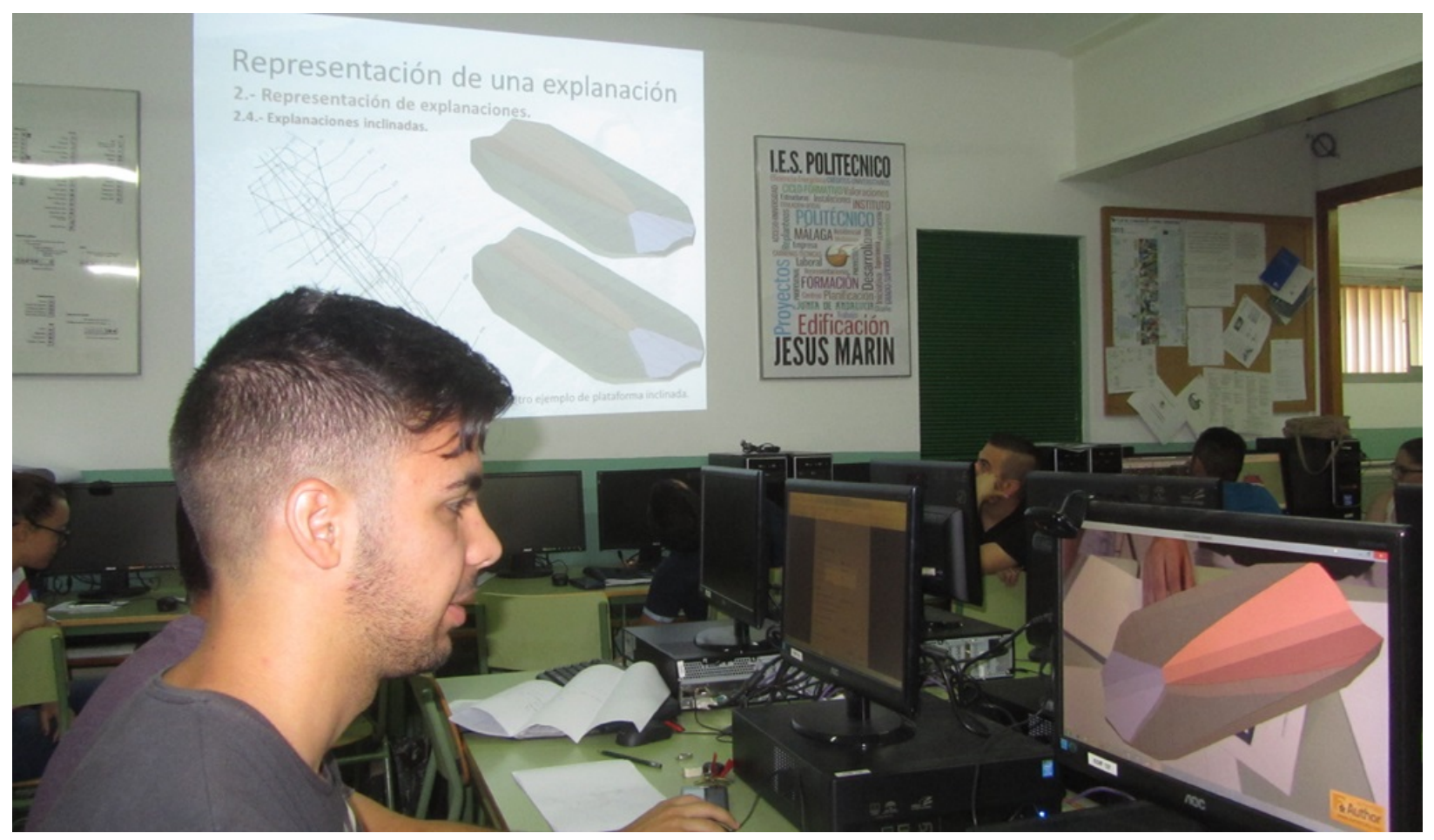

Figure 7. Using 3D model in the lecture in class.

\section{Final Assessment Test}

A questionnaire to assess the level of content acquisition and handling contours was completed.

\section{Comparative of academic results}

We have academic data from previous years, so we can compare the data obtained after applying 3D models in learning process to previous control data without using these models.

Most studies carried out concerning the improvement of spatial ability of students are related to the management of simple pieces or simple mechanical elements. It has not been observed applications to implement these techniques to terrain relief.

There are two manners of action regarding the evaluation of technologies of visualization 3D models. On the one hand, almost all of them have been made comparisons between a control group with another experimental, making a comparison between the two groups in terms of the variation of the spatial ability of students involved. In some of them, the gain that has been observed is statistically significant, but not in all cases. In our case, this procedure could not be done. The reason is because we have few students in one group and it is not possible the separation into two because of educational standards. Therefore, the comparison of visualization technologies was made within the same group, somewhat observed in other experiences with good results.

Something common among all experiences is very positive and receptive attitude observed in students in the treatment of these new technologies. The materials are always widely accepted.

\subsection{Grouping and Spaces}

It is necessary to have available a computer room. It is also possible to do these practices almost anywhere, using smartphones or tablets with specific applications.

\subsection{Hardware}

Technical requirements not very demanding: $1 \mathrm{~Gb}$ of graphics card.

\subsection{Software}

Used programs: office software, Adobe Acrobat 9 Pro Extended [34], CAD software, AutoCAD [35], Trimble SketchUp [36], Aumentaty Author, Viewer and app programs [37], Internet access and Moodle [38] to share information.

It was chosen SKP because it is free, easy, versatile and intuitive to use. It is possible to use the same in different contexts and, on the other hand, is a tool that lets you download a lot of three-dimensional models of the public gallery, which means it can be used by teachers from different areas of knowledge.

On the other hand, it seems that due to the same reasons of ease of use and versatility, PDF3D is a good choice for displaying three-dimensional elements. It is thought that it could become a standard, as it has happened with the pdf file format for reading documents. 


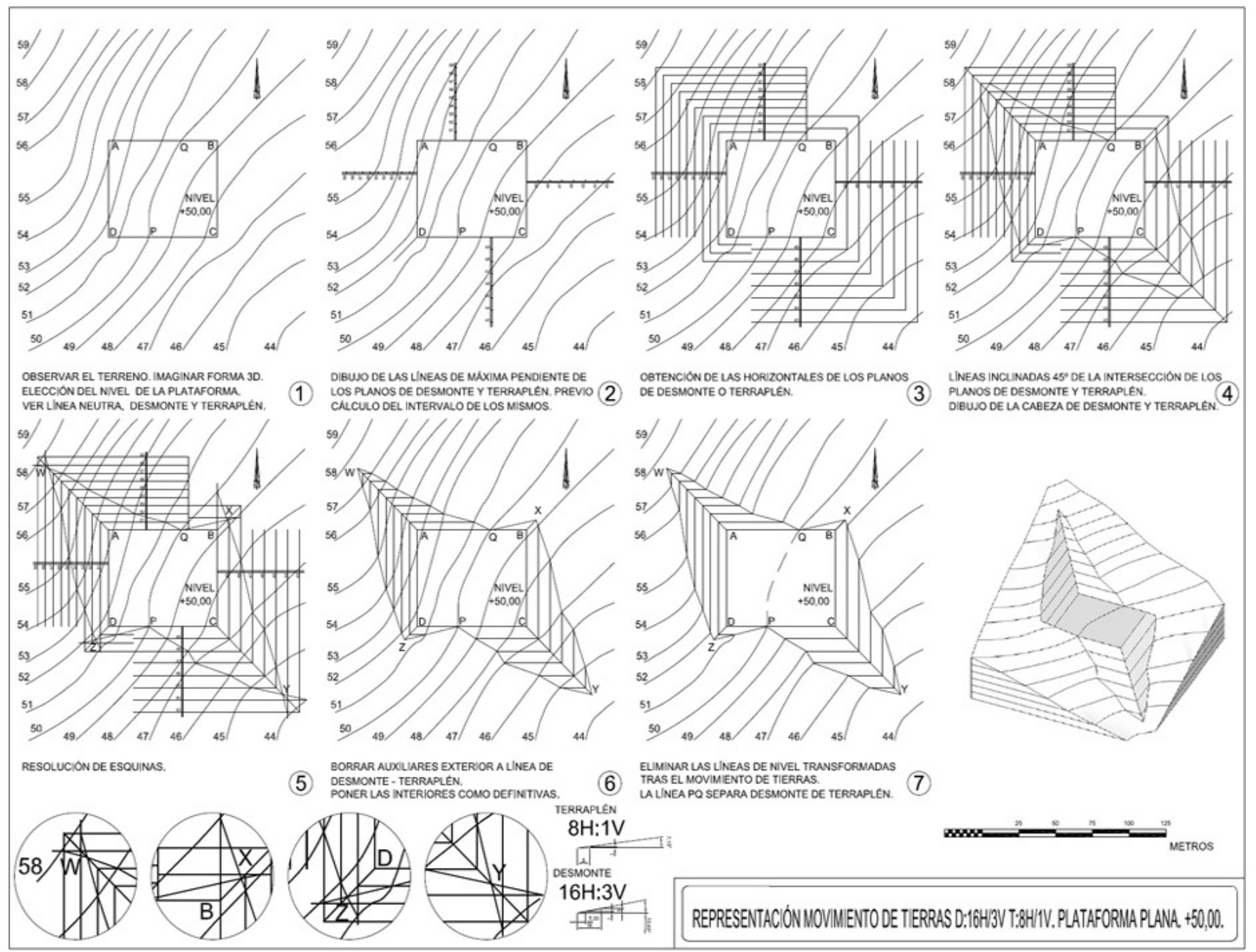

Figure 8. A guide which containing steps to guide students in the process.

Finally, it was looking for a tool that was intuitive, tangible, manageable with ICT and appealing. Something that would make them more involved in the task, with a digital language, similar to what students are accustomed. Once the visualization technology was found, i.e. augmented reality; the choosen program has been Aumentaty Author and Aumentaty viewer because it is free, secure and stable. These features have not been found in other options investigated.

\subsection{Auxiliaries}

Fiducial markers to display the items in AR, a worksheet and a guide which contain steps to guide them in the process, see Fig 8 . Thus students receive information in different ways reflected in Fig 9.

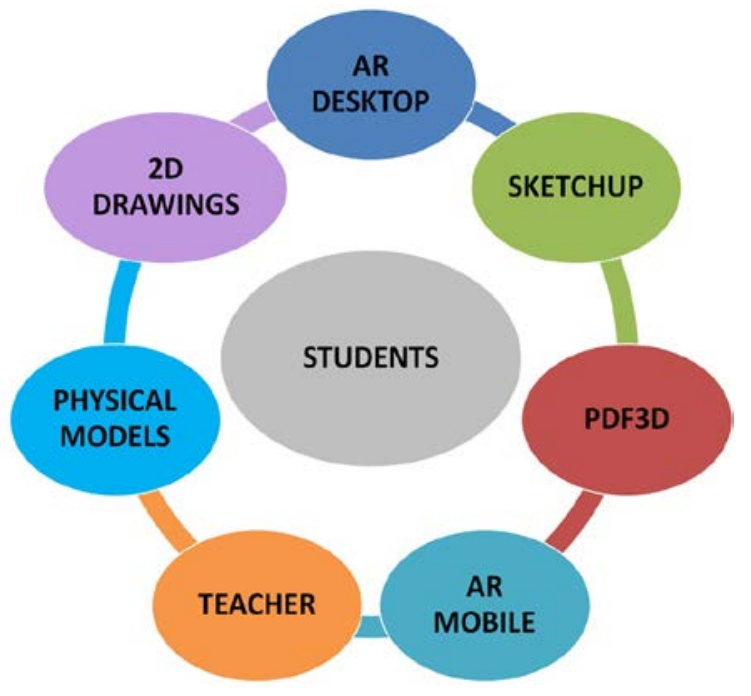

Figure 9. Ways of communication with the student. 


\subsection{Treated Material}

Material articulated in several themes that develop knowledge of contours along the course. Final objective: developing an urbanization plan of an area [39]

\section{Results and Discussions}

The first objective of this project is the delineation to establish the students' profile. Among them there are about 30 students per class at the beginning of the course, with more than $75 \%$ men, $80 \%$ of the total is less than 25 years.

To do this, at the beginning of the course students conducted a survey which consisted of several parts: ICT management, previous academic characteristics and basic knowledge of mathematics and drawing.

\subsection{Characterization of Students' Profile}

The first step was to know the level of ICT skills held by students to test the first hypothesis.

Technological profile can be seen from the questionnaire answered by the students.

It may be noted that all students have smartphone equipped with a screen with more than 3.5". More than 93\% of them have computer and $3 \mathrm{G}$ internet access, more than $60 \%$ have MP3 players or similar, console and digital camera but only $20 \%$ of them own a tablet. Moreover, most of them make daily use of mobile phones as well as the Internet; being used in $85 \%$ of the cases since two years or more.

The use of computers and mobiles is daily, from 2-4 hours on average, at home or at the study center, declaring such use for at least over two years by more than $70 \%$ of students. The majority of them is mainly engaged in study/work, shared with other uses such as hobbies or downloads using many applications, social networks and applications. The use of other devices lowers but this is supposed not to generate any problems as the functions of them are similar to mobiles but in a larger size.

Regarding their software management level is considered to have a medium-high level in the management of internet and half in office automation, being lower in the more specific programs.

It can be concluded that the results support the first hypothesis that students show a high technological level in the management of ICT. In addition, they handle a variety of devices after a short period of familiarization. Therefore, it is thought that the means used to observe 3D models will not be any hindrance to understand the knowledge associated to assimilate.

\subsection{Previous Academic Features}

At this point, students were asked for their academic and work history. Emphasizing detect its assessment as to their level on math and graphic expression, and more particularly to their skill in understanding and managing of contours in topography to contrast the second hypothesis.
During the course, a wide variety of students enrol, $70 \%$ from the different types of secondary schools, those who come after passing entrance exams for over 18 years $30 \%$, those who have tried to study first university degree courses $20 \%$ and to which the building boom in the labour market put out of the education system and are now returning to it in times of crisis 25\%. All of this supports the second hypothesis of the existence of a variety of mathematical and graphic knowledge required.

On the other hand, in general, students are quite comfortable with the subjects where the drawing is an important part, 4.23 and where mathematics is involved 3.53.

But it notes that they have more confidence about the use of mathematics than in their ability to solve graphic problems, preferring to perform simple calculations to complex ones, being more comfortable in understanding the plans than when they have to prepare them. To have a domain at ease of representation scales is the most difficult for them.

However, in general, the teachers observed that students' appreciations relating to the management of the mathematical and graphic materials are higher than the real, i.e., the self-concept of math skills exceeds the actual domain. This is evident in class exercises and the results of tests carried out and in other subjects of the course. This is an opinion that it is shared by the other teachers of the course.

Therefore, it is advisable to make a prior course, (8 hours), that deals with those mathematical and geometric elements developed along the course so that we do not encounter problems with the understanding of associated elements later. (Basic trigonometry, graduation of angles, scales, basic geometric layouts...).

As for the graphic part, most of students have no prior experience with contours or this is very low. However, in $90 \%$ of cases they are willing to improve that level.

\subsection{Parameters for Assessing These 3D Modelling Technologies}

A positive predisposition of students to the use of 3D models is observed. But it is noted the need to do some training before the use of such technologies (AR, SKP and PDF3D) because of their lack of knowledge.

Finally, using a formation based on ICT, students think that, in many cases, this is the most valued, easy to use, dynamic, intuitive and enjoyable, with a simple and clear language. On the other hand, the quantity and quality of material provided is also assessed, as well as subsequent professional use.

Many of these properties were subsequently measured in the satisfaction survey to study technologies, so it is believed that a large assessment of them have to responding to these needs.

\subsection{Surveys about Personal Opinion of Students}

The studies of each of the variables that make up the questionnaires were exposed. The goal is to obtain the views of students, regarding their level of satisfaction of 3D models 
used. They have been asked to perform an assessment on a Likert scale of 1-5 and make comments in different blocks:

\section{- Evaluation of the use of 3D models in general.}

On the use of 3D models it emphasizes that $100 \%$ of respondents would recommend the use of $3 \mathrm{D}$ models to explain the exercises of representation of terrain and earthworks for upcoming courses.

In fact, the overall assessment, table 1 and Fig. 10, for all technologies in use obtained values above 4 in all cases. Similar values were obtained in reference to its appeal, and being entirely clear and easier to understand. Values obtained were above 3.50 when students were asked about whether the exercises have been conducted autonomously or if they expect to do a better test.

Furthermore, students expressed their disagreement in many cases when asked if models have been considered an obstacle (1.88) or if they have not fulfill their expectations (1.73)

Moreover, it is stated that they are very practical and useful; being a way to visualize the teacher's explanation, making them see the solution of the exercises and the result before. They think that everything appears more understandable and in this way students find the answer to the questions that they have had more rapidly.

On the other hand, they point out that the means are very intuitive and they are allowed to see the models on all sides. Thus terrain irregularities and different parts of earthworks are better understood.

But on the contrary, a disadvantage is indicated: the comfort of not having to display the three-dimensional object in the mind, so the brain makes less effort in developing the intuitive ability to read a two-dimensional plan where a terrain is represented.

In conclusion, we can say that the recommendation of use by $100 \%$ of respondents, the high numerical ratings provided and comments made by the students, support the third hypothesis that students are satisfied with the support they receive from 3D models because they think they are useful for learning.

Table 1. Evaluation of the use of 3D models in general.

\begin{tabular}{|l|c|c|c|c|}
\cline { 2 - 5 } \multicolumn{1}{c|}{} & AR & PDF & SKP & MEAN \\
\hline 1. THERE WAS NO NEED OF ANYTHING ELSE. & 2.58 & 2.50 & 2.60 & 2.56 \\
\hline 2. IT IS EASIER TO UNDERSTAND. & 3.83 & 4.50 & 4.00 & 4.11 \\
\hline 3. EVERYTHING IS CLEAR. & 3.83 & 4.17 & 3.80 & 3.93 \\
\hline 4. I COMPLETE THE EXERCISES BY MYSELF. & 3.58 & 3.17 & 3.80 & 3.52 \\
\hline 5. FUNNIER AND ATTRACTIVE. & 3.92 & 4.33 & 4.40 & 4.22 \\
\hline 6. I WILL DO A BETTER EXAM. & 3.58 & 3.83 & 4.00 & 3.80 \\
\hline 7. IT DOESN'T RESPOND TO EXPECTATIONS. & 1.92 & 1.67 & 1.60 & 1.73 \\
\hline 8. LESS INTERESTING THAN TRADITIONAL. & 2.83 & 2.67 & 2.80 & 2.77 \\
\hline 9. WORSE VIEW THAN IN TRADITIONAL. & 2.83 & 2.83 & 2.80 & 2.82 \\
\hline 10. GENERAL ASSESSMENT. & 4.25 & 4.33 & 4.00 & 4.19 \\
\hline 11. THEY ARE AN OBSTACLE. & 1.83 & 2.00 & 1.80 & 1.88 \\
\hline
\end{tabular}

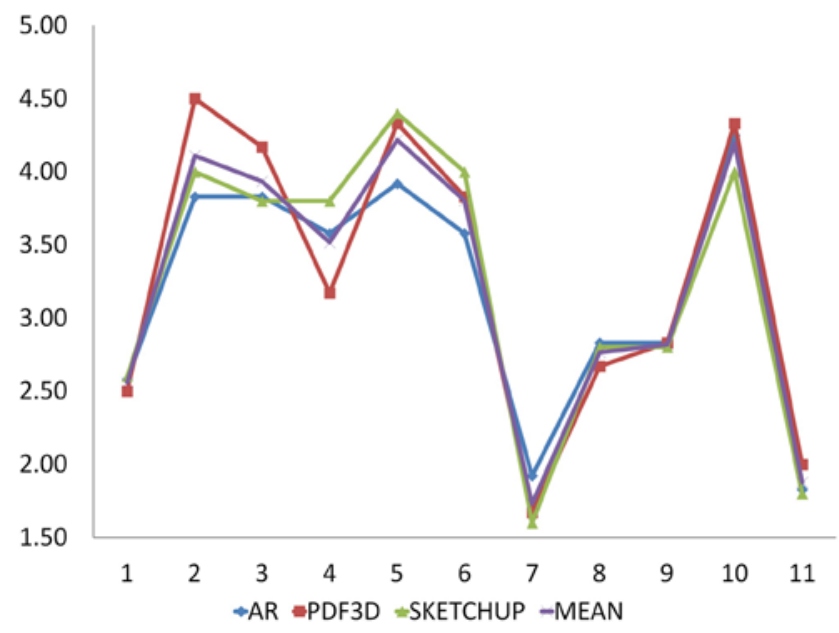

Figure 10. Evaluation of the use of $3 D$ models in general.

On the use of 3D models it emphasizes that $100 \%$ of respondents would recommend the use of 3D models to explain the exercises of representation of terrain and earthworks for upcoming courses.

In fact, the overall assessment, table 1 and Fig. 10, for all technologies in use obtained values above 4 in all cases. Similar values were obtained in reference to its appeal, and being entirely clear and easier to understand. Values obtained were above 3.50 when students were asked about whether the exercises have been conducted autonomously or if they expect to do a better test.

Furthermore, students expressed their disagreement in many cases when asked if models have been considered an obstacle (1.88) or if they have not fulfill their expectations (1.73)

Moreover, it is stated that they are very practical and useful; being a way to visualize the teacher's explanation, making them see the solution of the exercises and the result before. They think that everything appears more understandable and in this way students find the answer to the questions that they have had more rapidly.

On the other hand, they point out that the means are very intuitive and they are allowed to see the models on all sides. Thus terrain irregularities and different parts of earthworks are better understood.

But on the contrary, a disadvantage is indicated: the comfort of not having to display the three-dimensional object in the mind, so the brain makes less effort in developing the intuitive ability to read a two-dimensional plan where a terrain is represented.

In conclusion, we can say that the recommendation of use by $100 \%$ of respondents, the high numerical ratings provided and comments made by the students, support the third hypothesis that students are satisfied with the support they receive from 3D models because they think they are useful for learning.

\section{- Assessing the use of technology to display 3D models.}

Some students say there is not much difference in the three 
cases $40 \%$, commenting that all the technologies used has seemed very similar, since only differ in the way of manipulation. Also they note that they have understood the same with the three ways of display, in fact there are many similarities of score in the survey provided.

According to the data obtained, table 2 and Fig. 11, from the assessment carried out the biggest differences are observed in the appearance and in the flicker of image. Lower differences in values were obtained in the assessments concerning their speed and they seem to be useful.

In this final section, at least $88 \%$ of students considered good, $(>4)$, the assessment regarding the apparent usefulness of technology of used 3D models, independently of the technology used. So students report that the three ways of display have been very helpful and with all of them they achieve the same goal of understanding what is displayed.

Table 2. Assesing the use of technology to display 3D models.

\begin{tabular}{|l|c|c|c|c|}
\cline { 2 - 5 } \multicolumn{1}{c|}{} & AR & PDF & SKP & MEAN \\
\hline 1. GOOD APPEARANCE AND QUALITY. & 3.25 & 4.33 & 3.00 & 3.53 \\
\hline 2. STABLE. (NOT FREEZING). & 2.42 & 3.33 & 3.00 & 2.92 \\
\hline 3. NO FLICKERING. & 2.42 & 3.33 & 2.20 & 2.65 \\
\hline 4. QUICK. INSTANT. & 3.00 & 3.17 & 2.90 & 3.02 \\
\hline 5. EASY. COMFORTABLE. FAMILIAR. & 3.67 & 4.33 & 3.60 & 3.87 \\
\hline 6. THE SIZE WASN'T SUITABLE. & 3.33 & 4.00 & 3.80 & 3.71 \\
\hline 7. LEAVES MY HANDS FREE. & 3.50 & 4.17 & 3.80 & 3.82 \\
\hline 8. SHOWS VIEWS. & 3.58 & 4.50 & 4.10 & 4.06 \\
\hline 9. SEEMS USEFUL. & 3.92 & 4.17 & 3.90 & 4.00 \\
\hline
\end{tabular}

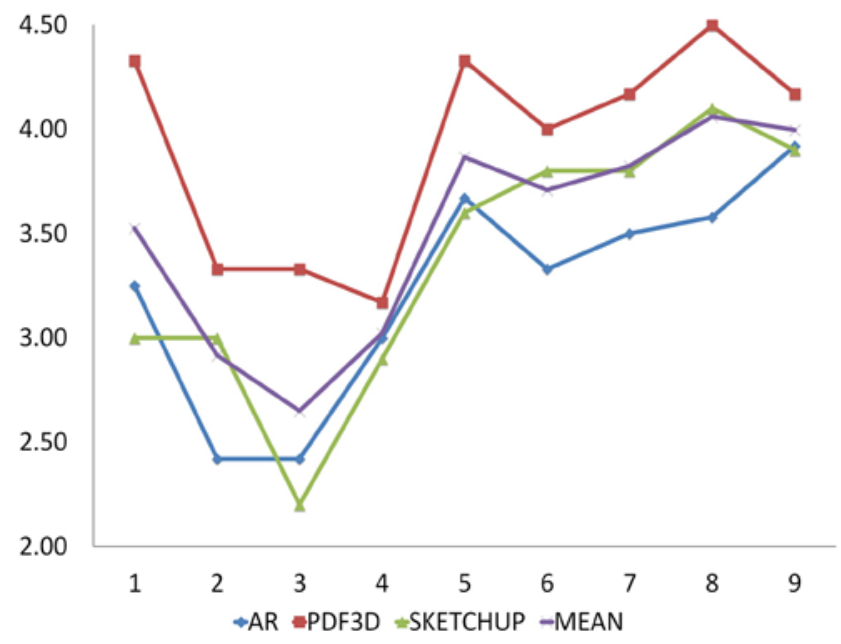

Figure 11. Assessing the use of technology to display 3D models.

The values obtained by the AR and SKP technologies are quite similar, 3.23 and 3.37, respectively. Furthermore, technology PDF3D (3.93) is shown as the most valued.

Some student said thanks to their previous studies, they did not need such technology to display three-dimensional elements so they considered that time invested was a disadvantage when preparing the technology, (positioning of the camera and loading the program), but they recognized for other students that it was a miracle to see certain items in 3D.

Moreover, it is said, AR does not always work well, because the image flickered, remained frozen or gave jumps or program failed, and needed to restart; so student has stopped using it during the teacher's explanation. This may be due to the quality of the devices, since it requires superior specifications other than that which we have available.

Regarding AR on mobile is indicated that models did not look very well, being of small size.

\subsection{Final Assessment Test}

It has carried out a comparison between the results of the initial and final tests in order to analyze the variation in the capacity of visualization and management of the contours by students.

An increased general understanding of the contours in all areas of its learning was observed. However, this variation is not constant, is higher when the drawings are more difficult to interpret, and lower when there are mathematical calculations associated, perhaps due to the difficulty of connecting the graphic and mathematical part. The rest of the themes have changed positively between $3.35 \%$ and $18.38 \%$.

\subsection{Comparative of Academic Results}

An improvement in academic results in the studied subject is observed from the incorporation of 3D models, however, those ratings includes other sections of learning, so it cannot be said that this increase is solely due to the incorporation of 3D models.

\section{Conclusions}

AR, computer programs, like PDF3D, or graphic design programs, such as SKP among others, allow students to handle and watch digital objects from different points of view and ways.

Differences due to the technologies and their possibilities of use are observed. All of these technologies are similar regarding zoom and turns, with minor differences between them. AR being perhaps the most striking because of its impact when students can see on screen the two realities, virtual and real, at the same time. However, regarding the management of them, SKP and PDF3D models are more versatile as they have direct buttons to obtain the views and profiles, whereas in AR, there must be as many different models as profiles is wanted to show on the screen.

On the other hand, AR models have presented some problems of flicker frozen image on the screen with relatively current equipment, though major limitations are not observed, provided that they have a good distribution and lighting.

Regarding the impact of the use of 3D models, it should be noted that it was important in terms of a decrease in the number of failures in the subject as well as a rise in the 
average percentage level of academic performance ratings of the students from the aggregation of these 3D models. This increase may not be completely attributed to the use of 3D models in the subject. Furthermore, on the other hand the size of the sample is small due to the characteristics of students, so that these results cannot be considered conclusive.

Finally, it can be concluded that the sense of both, the teaching staff and the students, has been very positive. This is because the models serve as a teaching resource to guide visualization and understanding of the contours by students, encouraging the active participation of them in the tasks, achieving more interaction in the classroom dynamics and in the compression of the work performed.

Therefore, it is thought that the success of these 3D models is due to the simplicity of connections between the two realities, being intuitive and attractive to students, without presenting any problem of distraction attributable to the media elements used.

Review of the model shows the great support that these visual aids contribute to the process of learning with deaf students, Fig. 12, improving real-time communication in the classroom and serving as helpful for understanding of the task to communicate.

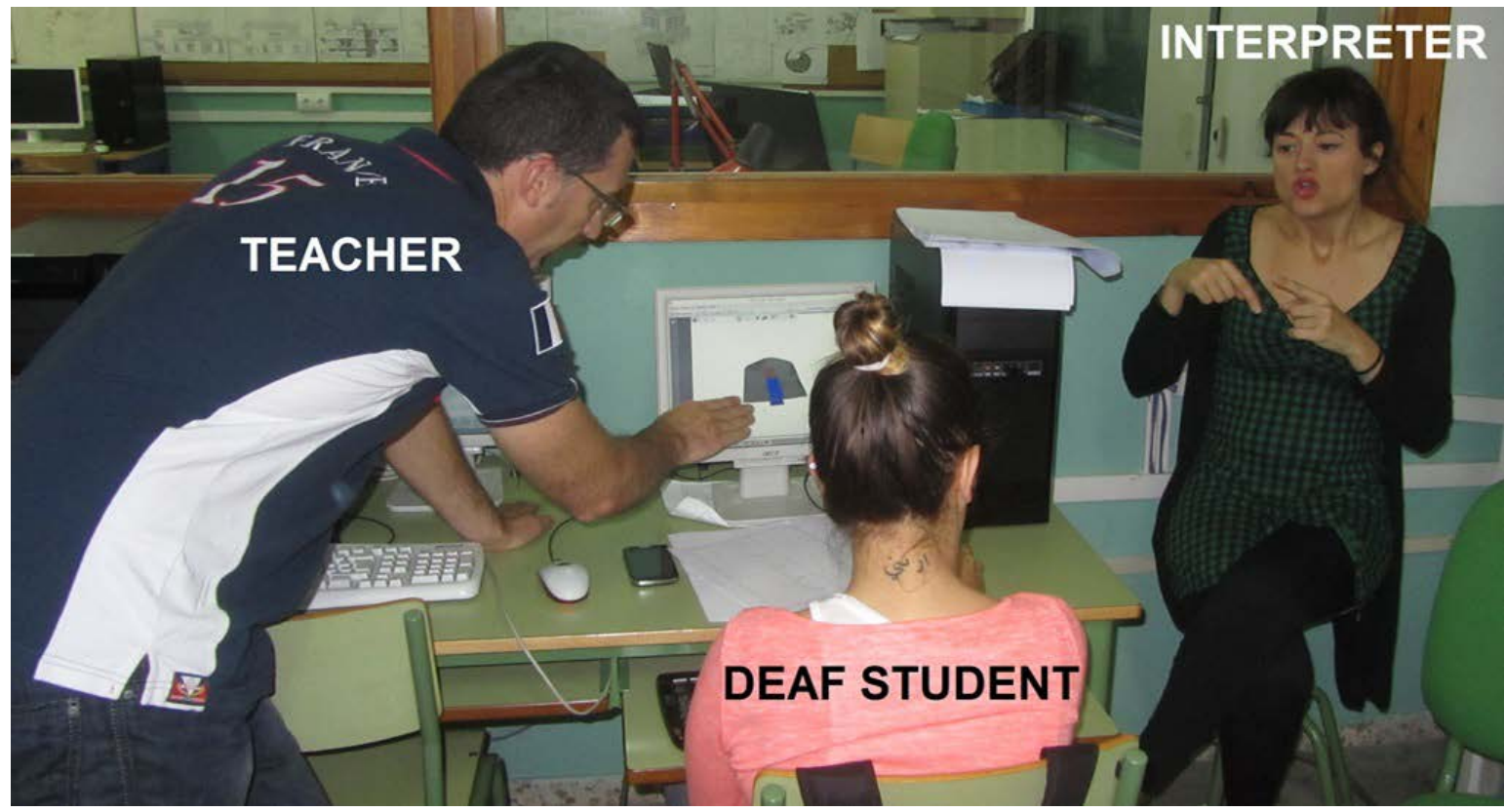

Figure 12. Using 3D models with deaf students in the learning process.

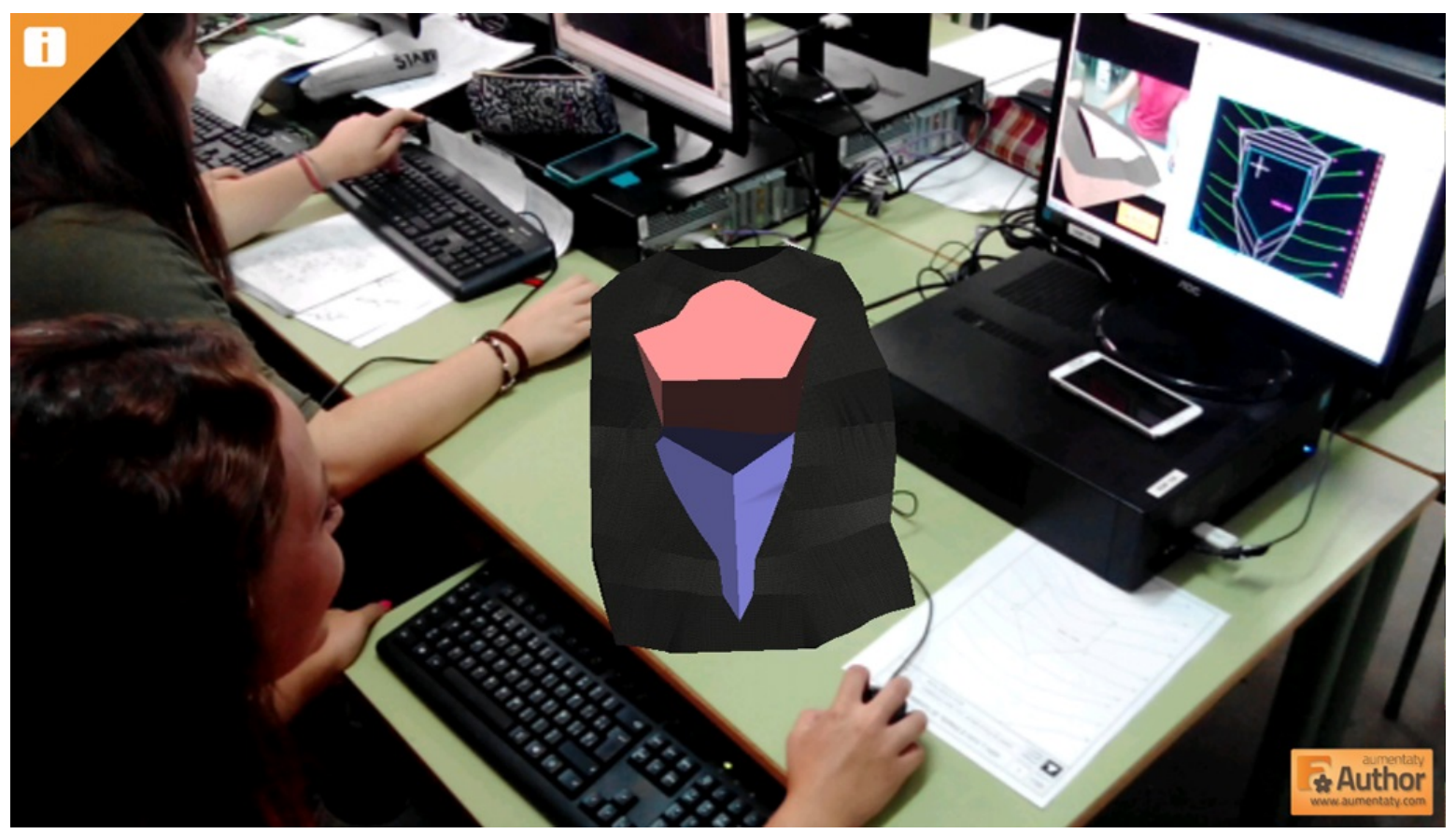

Figure 13. 3D models captured with Aumentaty app. 


\subsection{Future Works}

It would be interesting to take advantage of the popularity of new technologies such as 3D printing, and versatility of the Trimble ScketchUp models, which can be exported to formats *.stl extension, which are readable by 3D printers.

That is also the case of mobile phones or tablets, which thanks to its simplicity, mobility and comfort, along with the development of visualization applications, see Fig. 13, can offer new educational media to present these 3D models, provided that they have a size appropriate to maintain adequate levels of visual quality.

\section{Acknowledgements}

The Authors would like to thank all of the students who have collaborated on this study. Thanks to colleagues in our departments who have co-taught this course for several years, and to J. A Juango, I. López, E. Ramirez, S. Castillo, G. Jiménez D. W. Sumpter and I. Marcos who have helped bring this paper to completion.

\section{REFERENCES}

[1] S. Urdarevik, "Using models to teach and learn engineering," ASQ Advancing the STEM Agenda Conference, June 2013.

[2] Y. Chen, "Use of Tangible and Augmented Reality Models in Engineering Graphics Courses,” Journal of Professional Issues Engineering Education and Practice, 137 (4), pp. 267-276, 2011.

[3] J. Martín-Gutiérrez and M. Contero, "Mixed Reality for Learning Standard Mechanical Elements," 11th IEEE International Conference on Advanced Learning Technologies, pp. 372-3742011.

[4] J. Martín-Gutiérrez and M. Contero, "Improving academic performance and motivation in engineering education with augmented reality," CCIS HCI International, Orlando, Vol. 174, Part. 2, pp. 509-513, 2011.

[5] J. Martín-Gutiérrez, "Proposal of methodology for learning of standard mechanical elements using augmented reality," IEEE Frontiers in Education Conference (FIE), pp. T1J-1, 2011.

[6] H. Chen and K. Feng, "Application of Augmented Reality in Engineering Graphics Education,” ITME, Vol. 2, pp. 362-365, 2011.

[7] J. Martin-Gutierrez and M. Contero, "Improving Academic Performance and Motivation in Engineering Education with Augmented Reality,” Computer and Information Science, Vol. 174, pp. 509-513, 2011.

[8] M.S. Sidhu and W. Maqableh, "Dynamic simulation of a 3-D 4BL engineering problem using augmented reality,” IASTED International Conference on Advances in Computer Science and Engineering, ACSE, pp. 372-375, 2012.

[9] J. De la Torre, J.L. Saorín, C. Carbonell, M.D. Castillo, and
M.R. Contero, "Modelado 3D como herramienta educacional para el desarrollo de competencias de los nuevos grados de Bellas Artes,” Arte, Individuo y Sociedad, 24(2), pp. 179-193, 2012.

[10] C.H. Ko, T.C. Chang, Y.H. Chen, and L.H. Hua, "The application of augmented reality to design education," Edutainment Technologies. Educational Games and Virtual Reality/Augmented Reality Applications, pp. 20-24, 2011.

[11] E. Redondo, D. Fonseca, L. Giménez, G. Santana, and I. Navarro, "Alfabetización digital para la enseñanza de la arquitectura. Un estudio de caso,” Arquitetura revista, 8(1), pp. 76-87, 2012.

[12] M. Dobelis, "Information Communication Technologies in Architectural Education," Proceedings of the international conference on engineering education ICEE, pp. 25-29, July 2005.

[13] C.S.C. Rodrigues, "VisAr3D: An approach to software architecture teaching based on virtual and augmented reality," International Conference on Software Engineering, 2, pp. 351-352, 2010.

[14] A.S. Riera, E.R. Dominguez, and D.F. Escudero, "Developing an augmented reality application in the framework of architecture degree,” UXeLATE, pp. 37-42, 2012.

[15] E. Redondo, D. Fonseca, A. Sánchez, and I. Navarro, "New Strategies Using Handheld Augmented Reality and Mobile Learning-teaching Methodologies," Architecture and Building Engineering Degrees, Procedia Computer Science, 25, pp. 52-61, 2013.

[16] E. Redondo, A. Sánchez, J. Narcís, and J. Regot. "La ciudad como aula digital. Enseñando urbanismo y arquitectura mediante mobile learning y la realidad aumentada. Un estudio de viabilidad y de caso," ACE: Architecture, City and Environment, 7, No. 19 pp. 27-54, Junio 2012.

[17] R. Chen and X. Wang, “An Empirical Study on Tangible Augmented Reality Learning Space for Design Skill Transfer,” Tsinghua Science \& Technology, Vol. 13, No. 1, pp. 13-18, 2008.

[18] D. Batie, "Employing 3D sketchup graphic models for teaching construction drawing language," American Society for Engineering Education, ASEE Annual Conference and Exposition, 109, 2006.

[19] D. Fonseca, S. Villagrasa, F. Valls, E. Redondo, A. Climent, and L. Vicent, "Motivation assessment in engineering students using hybrid technologies for 3D visualization," Computers in Education (SIIE), International Symposium, pp. 12-14, 2014.

[20] A. H. Behzadan and V.R. Kamat, “A Framework for Utilizing Context-Aware Augmented Reality Visualization in Engineering Education," Conference on Construction Applications of Virtual Reality (CONVR), pp. 292-299, 2012.

[21] A.H. Behzadan and V. R. Kamat, "Integrated Information Modeling and Visual Simulation of Engineering Operations Using Dynamic Augmented Reality Scene Graphs,” Construction Innovation in Building (CIB), pp. 259-278, 2011.

[22] D.N. Rapp, S.A. Culpepper, K. Kirkby, and P. Morin, "Fostering students' comprehension of topographic maps," Geoscience Education, 55(1), pp. 5, 2007. 
[23] J. Babault, S. Bonnet, A. Crave, and J. Van Den Driessche, "Influence of piedmont sedimentation on erosion dynamics of an uplifting landscape: an experimental approach,” Geology, 33(4), pp. 301-305, April 2005.

[24] A. Feldman, M. L. Cooke, and M. S. Ellsworth, "The Classroom Sandbox: A Physical Model for Scientific Inquiry,” The Science Teacher, Vol. 77, No. 9, December 2010.

[25] L. Pinto, "Development of spatial skills through analog modeling of tectonic deformation," GSA Annual Meeting in Vancouver, October 2014.

[26] S. Whitmeyer, M. Feely, D. De Paor, R. Hennessy, S. Whitmeyer, J. Nicoletti, and M. Rivera, "Visualization techniques in field geology education: A case study from western Ireland,” Geological Society of America Special Papers, 461, pp. 105-115, 2009.

[27] C.R. González, J. Martín-Gutiérrez, M. G. Domínguez, A. S. HernanPérez, and C. M. Carrodeguas, "Improving Spatial Skills: An Orienteering Experience in Real and Virtual Environments With First Year Engineering Students," Procedia Computer Science, 25, pp. 428-435, 2013.

[28] S.C. Kuehn, "The topographic sand box, a tool for improved understanding and visualization of topographic maps," Geological Society of America Abstracts with Programs, vol. 44, No. 7, p.101, 2012.

[29] J.G. Lay and T.Y. Shih, "Enhancing students' ability in reading contour maps using GIS,” E-Learning Applications I, 90, June 2009.

[30] S. Reed, O. Kreylos, S. Hsi, L. Kellogg, G. Schladow, M.B. Yikilmaz, H. Segale, J. Silverman, S. Yalowitz, and E. Sato, "Shaping Watersheds Exhibit: An Interactive, Augmented Reality Sandbox for Advancing Earth Science Education,"
American Geophysical Union (AGU) Fall Meeting, ED34A-01, 2014.

[31] F.J. Ayala and J.A. Juango, "Mejora de las habilidades espaciales en expresión gráfica mediante el uso de la RA," Comunicación y Pedagogía, Vol. 279-280, pp. 26-32, 2014.

[32] E.P.S. Nunes, F.L.S. Nunes, R. Tori, and L.G. Roque, "An approach to assessment of knowledge acquisition by using three-dimensional virtual learning environment," IEEE Frontiers in Education Conference (FIE), pp. 22-25, 2014.

[33] F.J. Ayala, B. Parra, and F. Tubío, "From 2D to 3D: Teaching terrain representation in engineering studies through Augmented reality: Comparative versus 3D pdf," IEEE Frontiers in Education Conference (FIE), pp. 1263-1266, 2014.

[34] Adobe Systems Incorporated. Adobe Acrobat 9 Pro Extended, available at http://www.adobe.com/support/downloads/product.jsp?platf orm=Windows\&product=158, June 2015.

[35] Autodesk, Inc. Autocad, available at http://www.autodesk.es/products/autocad/overview,June 2015.

[36] Trimble Navigation Limited. Trimble SketchUp, available at http://www.sketchup.com/, June 2015.

[37] Aumentaty. Aumentaty Autor and Aumentaty Viewer, available at http://www.aumentaty.com/, June 2015.

[38] Moodle. Moodle, available at https://moodle.org/, June 2015.

[39] F.J. Ayala, B. Parra, F. Tubío, J.A. Juango, and S. Castillo, "Desarrollo de un plan parcial con realidad aumentada según la tipología de Edificios y los parámetros urbanísticos de un PGOU tipo”, Buenas prácticas con TIC, 2014. 